\title{
Behavioural response to interference competition in a sessile suspension feeder
}

\author{
Antonius Gagern*, Timo Schürg, Nico K. Michiels, Gregor Schulte, \\ Dennis Sprenger, Nils Anthes
}

\author{
Animal Evolutionary Ecology, Zoological Institute, Eberhard-Karls-Universität Tübingen, Auf der Morgenstelle 28, \\ 72076 Tübingen, Germany
}

\begin{abstract}
The sessile suspension-feeding worm-snail Dendropoma maxima Sowerby, 1825 (Vermetidae) secretes a mucous web to capture planktonic prey. In dense groups, the feeding webs of neighbouring snails frequently overlap and stick together. This may create direct food competition between neighbours because the earlier retracting snail may get more than its fair share of the prey. While field observations indicate that web overlap may generate retarded growth, we experimentally studied whether web overlap also triggers a phenotypic response in feeding behaviour. In our experiment we consecutively placed focal snails in a place by themselves (solitary) or close to a neighbouring snail such that webs overlapped, starting with either of the 2 conditions in half of the experimental individuals to exclude sequence effects. We found that focals retracted their feeding web significantly earlier when close to a neighbour than when solitary. Our experiments thus confirm a phenotypic response through early web retraction in D. maxima, indicating that direct interference competition affects worm-snail behaviour.
\end{abstract}

KEY WORDS: Phenotypic plasticity · Food competition · Suspension feeding $\cdot$ Prisoner's Dilemma

\section{INTRODUCTION}

Marine plankton feeders share access to a common food resource that may seem inexhaustible at first sight. Spatial and temporal variation in plankton availability, however, can generate food shortage, especially if population densities are high. Such density effects on preying efficiency and growth have been extensively studied in sessile suspension feeders (e.g. Peterson 1982, Sebens 1982, Peterson \& Black 1987, Patterson 1991, Anthony 1997). These animals cannot evade environmental fluctuations and may exhaust their own food resources by indirect inter-individual competition, in particular when plankton turnover is restricted (e.g. Hughes 1979, Peterson \& Black 1987, Wilson 1990).

Food competition among suspension feeders obtains an intriguing and rarely studied additional dimension in systems where the feeding mechanism provides scope for direct competition between neighbours (Wilson 1990). One such example is the vermetid gastropod Dendropoma maxima Sowerby, 1825 (Vermeti- dae), a passive suspension feeder (Jørgensen 1966, LaBarbera 1984). Living in a permanent calcareous tube, these worm-snails secrete a sticky mucus web that is spun from the pedal tentacles and spreads by ambient water flow to cover the surrounding substrate. During exposure, plankton particles are caught in the web. After approximately $20 \mathrm{~min}$, the web is retracted using the jaws and rotation of the head and ingested using the radula (Hadfield et al. 1972, Hughes \& Lewis 1974). The whole feeding cycle (FC), which includes web secretion, exposure and retraction, takes approximately 35 min (Kappner et al. 2000).

In dense worm-snail aggregations, neighbouring webs frequently overlap and stick together (Hughes 1979). In such cases, Smalley (1984) found individuals to be smaller (using operculum diameter as a proxy) than at low densities. Following experimental reduction of population density, total web area within aggregations remained constant, i.e. average web area per individual increased (Smalley 1984). This indicates that small body sizes at high densities are a 
direct consequence of web overlap, which may reduce foraging success and thus growth. Such negative effects of web overlap could be either alleviated or reinforced if individuals actively adjusted feeding behaviour to fluctuations in their competitive environment. In a different context, the principal ability of Dendropoma maxima to respond flexibly to environmental fluctuations has already been shown (Kappner et al. 2000). The individual rate at which the web is drawn in (web retraction frequency, WRF) increases with plankton density, such that an approximately constant food amount is ingested per FC (Kappner et al. 2000, Ribak et al. 2005). The present study investigates whether worm-snails are also capable of adjusting feeding behaviour to the absence or presence of direct competition with a neighbour. When webs overlap, direct competition is plausible because early web retraction may allow snatching parts of the neighbour's web. Some earlier reports of FCs being synchronised and shorter between neighbours (Hughes \& Lewis 1974, Hughes 1978, Kappner et al. 2000) are indicative of such effects. We tested experimentally whether web overlap indeed triggers earlier web retraction in $D$. maxima.

\section{MATERIALS AND METHODS}

Field work was conducted in the Red Sea on the reef flat of Mangrove Bay (Sharm Fugani), $30 \mathrm{~km}$ south of El Quseir (Egypt). Here, Dendropoma maxima is very common on the reef crest, using fire corals (genus Millepora) as the main substrate, and on the reef flat, where individuals are often attached to blocks of dead coral rubble. This latter feature makes $D$. maxima very convenient for field experiments.

Field observations: proximity to neighbour and feeding behaviour. In September 2004, we measured the distance to the nearest neighbour in 20 focal individuals along a $50 \mathrm{~m}$ reef section in 0.3 to $1.5 \mathrm{~m}$ depth. For each focal, we further recorded the number of web retractions during each of 7 observations, each lasting $71.7 \pm 15.6 \mathrm{~min}$ on average, over the course of $7 \mathrm{~d}$. WRF was calculated as the number of web retractions per observation divided by the respective observation duration (in h). We then checked for a correlation between nearest neighbour distance and the average WRF per focal. To assess whether this correlation may have been confounded by size effects, we subsequently measured and correlated operculum diameter (in $\mathrm{mm}$ ) and the distance to the nearest neighbour in another 127 individuals along the same transect. Since data distributions deviated from the assumptions of normality, we conservatively performed Spearman rank correlations for these analyses.
Experiment: individual plasticity in feeding behaviour. To test whether individuals adjust their WRF to the presence or absence of a neighbour, we conducted a manipulative study in October 2006 on the reef flat in $1 \mathrm{~m}$ water depth, where we exposed focal snails to the following 2 conditions on 2 subsequent days:

(1) Solitary: $50 \mathrm{~cm}$ distance to the nearest neighbour, excluding overlap between feeding webs (maximum web length = 12 cm; Smalley 1984, T. Schürg pers. obs.).

(2) Pair: 3 to $5 \mathrm{~cm}$ distance to one neighbour, such that their webs overlap.

Testing the same individuals under both conditions represents a pair-wise statistical design, which corrects for the effects of inter-individual variation in size and feeding behaviour.

We split the experiment into 4 runs with 10 focal snails each. Within each run, we excluded environmental variation between measurement days by simultaneously starting the solitary treatment ( $\mathrm{n}=5$ focals) and the pair treatment ( $\mathrm{n}=5$ focals). After the first measurement, focals were swapped to the alternative treatment for the second measurement. Each single experimental run was conducted within a single small $\left(>10 \mathrm{~m}^{2}\right)$ planar area on the central reef flat $(0.5 \mathrm{~m}$ depth). Replicates of either treatment were alternated in space in order to minimize confounding effects of variation in environmental conditions, e.g. spatial variation in plankton density between different parts of the reef flat (cf. Kappner et al. 2000). The first 2 experimental runs were performed in parallel at 2 adjacent sites (10 $\mathrm{m}$ apart), one in the morning at incoming tide, and one in the afternoon at outgoing tide, following the protocol outlined below. This scheme was repeated for the remaining 2 runs, yielding a total $n=40$.

Day 1: Collection of 20 focal snails living by themselves (solitary, i.e. no neighbour within $50 \mathrm{~cm}$ radius) on a large piece of moveable coral rubble. These focals had not experienced web overlap at their place of origin, an $80 \mathrm{~m}^{2}$ exposed back reef at 0.2 to $1.2 \mathrm{~m}$ water depth. All focals were marked individually with coloured cable binders and allocated to either of 2 experimental runs. Within a $10 \mathrm{~m}^{2}$ observation arena, focals were placed next to an uninhabited coral block (solitary treatment) or close to a coral block which was inhabited by 1 resident snail, which now served as the focal's novel neighbour (pair treatment). Focals from the 2 treatments were spatially alternated to avoid any spatial bias in water quality between experimental groups.

Day 2: The first FC measurement was made on this day. We recorded the exact times when a focal snail started web haul-in. This conspicuous movement is initiated by lifting the pedal tentacles beyond the edge of the shell aperture and sucking in the web. Each observation period took 60 min or until all focals had completed at least 2 FCs. Following these measurements, 


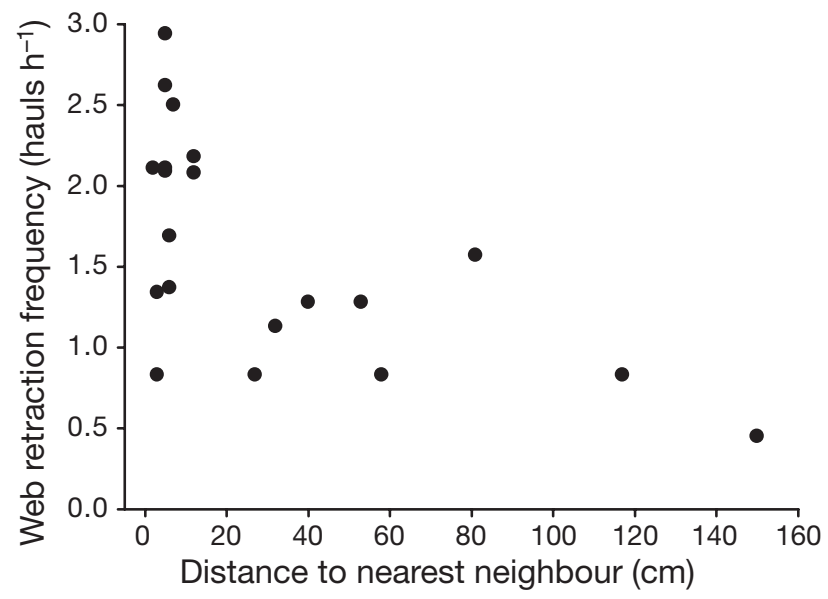

Fig. 1. Dendropoma maxima. Web retraction frequency in relation to nearest neighbour distance. Spearman rank correlation $r_{\mathrm{S}}=-0.555, \mathrm{n}=20, \mathrm{p}=0.011$

we switched the positions of focal snails within the observation arena such that all 'solitary' snails now had a neighbour and all 'pair' snails were now solitary.

Day 3: Snails were left untouched to acclimate.

Day 4: The second FC measurement of the newly positioned worm-snails was made on Day 4. All focal snails were subsequently returned to their place of origin.

Days 5 to 8: Iteration of the whole procedure for the last 2 runs.

Three focals lost their individual markers, 1 did not haul in its web during observation, and 2 were touched by accident. These individuals were excluded from all analyses, leaving 34 independent data points.

The $2 \times 2$ runs did not differ in mean FC duration and data were therefore pooled. Mean individual FC durations under the solitary and group treatments were then compared using a paired $t$-test across runs, adding experimental sequence (solitary $\rightarrow$ pair or pair $\rightarrow$ solitary) as a grouping variable. All statistics were calculated with JMP IN 5.1.2 (SAS Institute, available at: www.jmpin.com).

\section{RESULTS}

\section{Field observations}

In line with the hypothesis that worm-snails adjust web retraction to intraspecific competition, WRF in Dendropoma maxima decreased significantly with the distance to the nearest neighbour (Spearman rank correlation $r_{\mathrm{S}}=-0.555, \mathrm{n}=20, \mathrm{p}=0.011$, Fig. 1). WRF was particularly high with neighbours less than $10 \mathrm{~cm}$ apart, such that webs overlapped. However, wormsnails with a close neighbour were also smaller than solitary individuals $\left(r_{\mathrm{S}}=0.409, \mathrm{n}=127, \mathrm{p}<0.001\right.$,

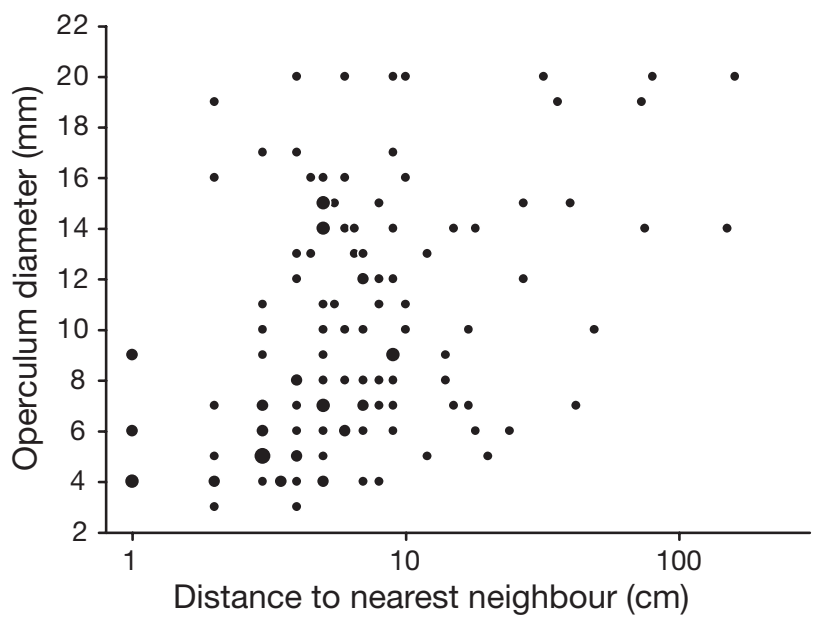

Fig. 2. Dendropoma maxima. Operculum diameter in wormsnails in relation to nearest neighbour distance (note logscale). Dot size indicates the number of individuals (max. 6) with identical values. Spearman rank correlation $r_{\mathrm{S}}=0.409$, $\mathrm{n}=127, \mathrm{p}<0.001$

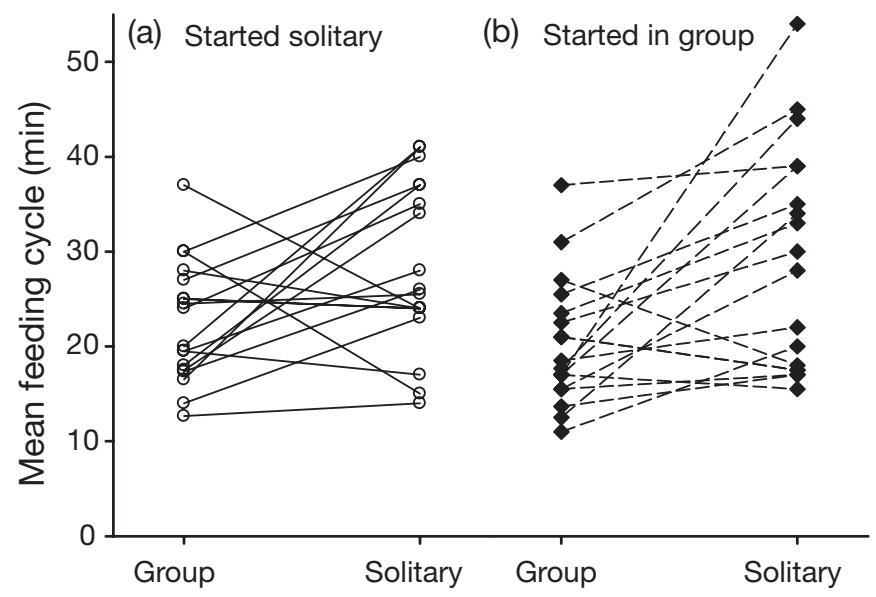

Fig. 3. Dendropoma maxima. Mean feeding cycle duration of focal snails in the group versus the solitary treatment. Lines connect mean values per focal. Paired $t$-test, $t_{33}=4.06, \mathrm{p}=$ 0.0003 , with no effect of experimental sequence (test across groups, $F=0.812, \mathrm{p}=0.37$ )

Fig. 2), leaving the possibility that increased WRF was a consequence of size and not of competition.

\section{Experiment}

Focal Dendropoma maxima flexibly adjusted feeding behaviour to changes in their competitive environment. Feeding cycles were significantly shorter when paired to a close neighbour with overlapping webs than when solitary (paired $t$-test, $t_{33}=4.06, \mathrm{p}=0.0003$, with no effect of experimental sequence: test across groups $F=0.812$, p =0.37; Fig. 3). 


\section{DISCUSSION}

We found that FCs in Dendropoma maxima were shorter in the presence of a close neighbour. Such phenotypic plasticity in response to a novel competitive situation complements earlier reports that $D$. maxima adjusts FC duration to prey density (Kappner et al. 2000, Ribak et al. 2005). Our data match the hypothesis of direct interference competition between neighbouring $D$. maxima. The individual that retracts earlier than its neighbour increases its pay-off by ingesting more than its fair share of the overlapping web (cf. Hughes 1979, 1985). This should yield more prey, providing a direct energetic benefit. The individual that retracts late suffers a reduced pay-off because some of the time and energy invested in web production has been lost to the neighbour.

Despite the obvious immediate benefits, early web retraction is likely to reduce the long-term feeding efficacy of both neighbours. Because worm-snails tend to synchronise their behaviour (Hughes \& Lewis 1974, Hughes 1978, Kappner et al. 2000), average FC duration will decrease under direct competition (as shown here), whereas the time and energy required for hauling, digesting, fabricating, and ejecting the web remains unchanged. This lowers the ratio of foraging to handling time, making foraging even less effective than it already is when neighbouring webs overlap (Smalley 1984). Interference competition between worm-snail neighbours resembles a classic repeated Prisoner's Dilemma (Axelrod \& Hamilton 1981, Maynard-Smith 1982): defining web retraction at the energetically optimal time as the 'cooperate' decision, an individual that defects and retracts a little earlier may gain a small instant benefit. Because cooperation is always susceptible to earlier retraction by the partner (defection), the only evolutionarily stable strategy in a one-shot game would be defection by both neighbours, even though defection yields a lower benefit for either individual than mutual cooperation. However, as neighbours interact repeatedly with each other, a cooperative solution would be possible in theory (Axelrod \& Hamilton 1981). It is therefore interesting to note that our data indicate that individuals do not cooperate. Future evaluation of worm-snail feeding behaviour in the context of cooperation theory is required to understand this result.

Given that our findings indicate a cost of groupliving, it is interesting to note that many vermetids, including Dendropoma maxima, typically form large aggregations (e.g. Hadfield et al. 1972, Hughes 1979, Zuschin et al. 2001). Possibly, the necessity to settle in an environment with sufficient food may actually override the potential decline in feeding efficiency due to competition. Passive suspension feeders require continuous water supply, and optimal habitats may be restricted to the exposed and turbulent parts of topographically structured environments such as coral reefs (e.g. Ribak et al. 2005). The smaller size of worm-snails in aggregations (Smalley 1984, present study) may have various reasons: (1) decelerated growth may be imposed by the lower preying efficiency of overlapping webs (Smalley 1984) and the effects of direct interference competition (present study); (2) if larger animals produced larger webs, an 'active' decision to stay small and maintain web overlap to a minimum may be the most efficient strategy in dense groups; and (3) limited growth may be an optimal solution for the trade-off between growth and reproduction under restricted food conditions (Sebens 1982). Current evidence does not allow us to distinguish between these alternatives. Compensating benefits of an aggregated lifestyle have not yet been demonstrated, but anecdotal observations indicate they may exist (see also discussion in Hughes 1979). During our experimental study, solitary worm-snails tended to retract their webs completely, whereas paired snails sometimes maintained contact to their neighbour's web. This only makes sense if maintaining web connection provides some benefits, such as increased resistance against disruption by wave action or an elevated preying efficiency per unit web surface area through changes in its physical traits (as suggested by Best 1988). No study to date has assessed whether such benefits exist in worm-snails.

Our study offers scope for future empirical and theoretical work. First, the costs associated with direct interference need to be established. Important measures include the delay of retraction of partners if their neighbour retracts early, the amount of food and web resources that are lost if retracting late, the relationship between body size, web size and FC duration (e.g. Hughes 1978), the long-term effects of density on growth in experimental enclosures (Peterson \& Black 1987), and the effect that web overlap has on its physical, prey-capture-related properties (LaBarbera 1984, Best 1988). Second, the proximate mechanisms that worm-snails employ to assess a neighbour's pull to the overlapping net should be identified, along with whether they can differentiate these from the drag generated by a full web (Boettger 1930). Finally, theoretical models should generate testable predictions to contrast optimal feeding behaviour under pure energetic considerations with interference competition in a Prisoner's Dilemma-like situation, and thus help understanding the ultimate reasons for phenotypic plasticity in feeding behaviour. 
Acknowledgements. We thank the team at Duck's Dive Centre in Mangrove Bay for their great hospitality and support. R. Bshary provided helpful comments on an earlier draft of this manuscript. Field work reported in this study was conducted under a National Parks of Egypt letter of agreement to Thomas Hülsken (University of Bochum, Germany).

\section{LITERATURE CITED}

Anthony KRN (1997) Prey capture by the sea anemone Metridium senile (L.): effects of body size, flow regime, and upstream neighbors. Biol Bull (Woods Hole) 192:73-86

Axelrod R, Hamilton WD (1981) The evolution of cooperation. Science 211:1390-1396

Best BA (1988) Passive suspension feeding in a sea pen: effects of ambient flow on volume flow rate and filtering efficiency. Biol Bull (Woods Hole) 175:332-342

Boettger CR (1930) Studien zur Physiologie der Nahrungsaufnahme festgewachsener Schnecken. Die Ernährung der Wurmschnecke Vermetus. Biol Zentrbl 50:581-598

Hadfield MG, Kay EA, Gillette MU, Lloyd MC (1972) The Vermetidae (Mollusca: Gastropoda) of the Hawaiian Islands. Mar Biol 12:81-98

Hughes RN (1978) The biology of Dendropoma corallinaceum and Serpulorbis natalensis, two South African vermetid gastropods. Zool J Linn Soc 64:111-127

Hughes RN (1979) Coloniality in Vermetidae. In: Larwood GP, Rosen BR (eds) Biology and systematics of colonial organisms. Academic Press, University of Durham, London, p 243-254

Hughes RN (1985) Feeding behaviour of the sessile gastropod Tripsycha tulipa (Vermetidae). J Molluscan Stud 51: 326-330

Hughes RN, Lewis AH (1974) On the spatial distribution, feeding and reproduction of the vermetid gastropod Dendropoma maximum. J Zool 172:531-547

Editorial responsibility: Roger Hughes (Contributing Editor), Bangor, UK
Jørgensen CB (1966) Biology of suspension feeding, Pergamon Press, Oxford

Kappner I, Al-Moghrabi SM, Richter C (2000) Mucus-net feeding by the vermetid gastropod Dendropoma maxima in coral reefs. Mar Ecol Prog Ser 204:309-313

LaBarbera M (1984) Feeding currents and particle capture mechanisms in suspension feeding animals. Am Zool 24: $71-84$

Maynard-Smith J (1982) Evolution and the theory of games. Cambridge University Press, Cambridge

Patterson MR (1991) Passive suspension feeding by an octocoral in plankton patches: empirical test of a mathematical model. Biol Bull (Woods Hole) 180:81-92

Peterson CH (1982) The importance of predation and intraand interspecific competition in the population biology of two infaunal suspension-feeding bivalves, Protothaca staminea and Chione undatella. Ecol Monogr 52: $437-475$

Peterson CH, Black R (1987) Resource depletion by active suspension feeders on tidal flats: influence of local density and tidal elevation. Limnol Oceanogr 32:143-166

Ribak G, Heller J, Genin A (2005) Mucus-net feeding on organic particles by the vermetid gastropod Dendropoma maximum in and below the surf zone. Mar Ecol Prog Ser 293:77-87

Sebens KP (1982) The limits to indeterminate growth: an optimal size model applied to passive suspension feeders. Ecology 63:209-222

Smalley TL (1984) Possible effects of intraspecific competition on the population structure of a solitary vermetid mollusc. Mar Ecol Prog Ser 14:139-144

Wilson WH (1990) Competition and predation in marine soft-sediment communities. Annu Rev Ecol Syst 21: 221-241

Zuschin M, Hohenegger J, Steininger FF (2001) Molluscan assemblages on coral reefs and associated hard substrata in the northern Red Sea. Coral Reefs 20:107-116

Submitted: May 11, 2007; Accepted: August 8, 2007

Proofs received from author(s): January 2, 2008 